\title{
Manufacturer Profit Maximum Model in a Supply Network
}

WANG Zhen-feng ${ }^{1, a}$, WANG Zhan-w ${ }^{2, b}$, XU Guang-yin ${ }^{3, c^{*}}$

\begin{abstract}
${ }^{1}$ Collaborative Innovation Center of Biomass Energy, Henan Province, College of Mechanical and Electrical Engineering, Henan Agricultural University, Zhengzhou, 450002, China

${ }^{2}$ Collaborative Innovation Center of Biomass Energy, Henan Province, College of Mechanical and Electrical Engineering, Henan Agricultural University, Zhengzhou, 450002, China

${ }^{3}$ Collaborative Innovation Center of Biomass Energy, Henan Province, College of Mechanical and Electrical Engineering, Henan Agricultural University, Zhengzhou, 450002, China

aemail: zhenfengking@163.com,, ${ }^{\mathrm{b}}$ email: wzw215824393@163.com, ${ }^{\mathrm{c}}$ email: xgy4175@126.com
\end{abstract}

Keywords: Demand Uncertainty; Supply Network; Manufacturing Costs; Penalty Parameter.

\begin{abstract}
A supply network has been studied which consists of a supplier and a manufacturer. Considering inventory costs and shortage cost because of supply shortage, profit maximum model was established based on the uncertain market demand and variable manufacturing costs. The feasibility of the model has been proved by Numerical Analysis.
\end{abstract}

\section{Introduction}

Uncertainty refers to the process or the result of a certain thing is not known in advance, in other words the outcome of the event is a lot of possibilities, and there is no predictability, and cannot be accurate observation, so there are many uncertainty. Enterprises in the process of the formation of the supply chain, due to the information network is perplexing and the market demands is changeable, leading to uncertain information and also because of the social, economic and political endures in the presence of uncertainty factors, leading to the uncertainty of the supply chain. Due to the uncertainty of the market analysis, the manufacturer cannot produce quantitative products. Suppliers in an uncertain market environment, cannot store a lot of products. Demand and supply chain are closely linked, in order to maximize the profits of the business, it should study this profit model.

The match between supply and demand is crucial in order to achieve effective supply chain management ${ }^{[1,2]}$. The supply network does not match supply and demand because of the intense competition and rapid market changes, the uncertainty of customer demand. This requires the enterprises to make effective management of the supply chain. In today's era of economic globalization, enterprises cannot be separated from the group and exist alone, the development of enterprises need to cooperate with each other. Enterprises need to strengthen the management of the supply chain that not only can improve the production capacity of enterprises but also can improve the level of customer service. Effective supply chain management is beneficial to enterprises to find the nodes which hinder the development of the production. It can help the enterprise to found the bottleneck of the production line, clear the shortcomings of enterprise supply chain and enterprises can understand customer needs and provide professional service by supply chain management.

For adapting to the environment, it is important to understand the environment and future trends, and analysis and response capabilities to the uncertain event ${ }^{[3]}$. In the supply chain of different nodes have different enterprises which have different nature, different characteristics, different roles and the impact on the supply chain is also different. Leading enterprises as the main role in the supply chain, it promoting the operation of the entire supply chain. The leading enterprise is the center of the adjustment of organizational structure of the supply chain, based on the development of external economic environment and their own requirements timely adjustment of the organizational structure of enterprises. Leading enterprises is the information exchange center. It plays a decisive role in the effective flow of information on the supply chain operation. Enterprise as the exchange center of information should first promote information sharing in the supply chain 
and to promote the information effective transfer. Leading enterprises is the control center of the response cycle. In today's society production relate are closely, but the cooperation between the enterprises existing time difference, operational pace inconsistent. Leading enterprises under the assistance of all the enterprises in the supply chain can control response time, ensure the development of supply chain. And the enterprise supply chain profit model analysis and coordination requirements the node enterprises inventory management ideas and methods from the traditional only focus on its own local inventory management steering on the whole supply chain, from the traditional logistics control based inventory management to inventory management based on process control ${ }^{[4]}$. In the decentralized supply network, members tend to consider their decision-making profits ${ }^{[5]}$. In this context, manufacturers of the supply network should maximize their returns from a systems perspective. This paper studies a supply network consisting of a supplier and a manufacturer, and established Manufacturer profit model based on, demand and manufacturing costs under uncertainty.

In the condition of market economy, enterprise supply chain management is through the close cooperation between the trade partners, provide maximum value to customers at the lowest cost, which requires the supply chain link the activities of enterprises should be carried out simultaneously, rather than dispersed, control method obviously tradition has been unable to meet the demand and supply chain management. In the research of $\mathrm{Hu} \mathrm{Jia,} \mathrm{he} \mathrm{first} \mathrm{discusses} \mathrm{the}$ significance of strengthening the supply chain management of enterprises under the market economy, and then analyzes the profit model of enterprise supply chain under market economy ${ }^{[6]}$.

In the research of Li Gui-chun, he pointed out that the supply chain system could be classified into the centralized and distributive ones. The centralized supply chain system allowed for the performance optimization of the supply chain, where the centralized control ensured the efficiency of the system, but was rather infeasible. In contrast, the distributive supply chain system composed of several members concerned with maximizing their own profit, thus increasing the difficulty in optimizing the overall benefit of the supply chain. As a result, a coordination mechanism was necessary for the decision-makers who pursued means of coordination ${ }^{[7]}$.

The theory and method of Markov chain is from the object of study in different time state of study and describe the possibility of transfer between the states and studied all the change process, to study the state of development of the object in future prediction. Based on the application of Markov chain in real life is random, no effect and stability. Its application field is very extensive, especially in the forecast aspect has the important practical value. This method can greatly improve the accuracy of prediction, and can predict the occurrence trend of super long period, so as to provide a reference for the establishment of scientific optimal decision scheme ${ }^{[8]}$. Some scholars have applied the theory and method of Markov chain to sales and profit forecasts, these methods can forecast market share rate, the future market trend and competitor trend, profit,. And the method is simple and convenient, easy popularization, high accuracy, for enterprise decision makers understand changes in the market, scientific decision-making provide long-term effective basis, has important practical value.

\section{Construction of the Profit Model}

Before establishing a profit model, we first understand the concept of price sensitivity coefficient, variable cost coefficient and penalty factor.

Price sensitivity coefficient refers to the elastic function of customer demand, that is, the change of product demand caused by price fluctuation. Since markets are highly dynamic and uncertainty, the quantification of this data often cannot be directly used as basis for the development of marketing strategy and sometimes misleading the management strategy of the enterprise. Research the psychology of consumer about consumer prices and understand the consumer price sensitivity of influencing factors can enable enterprises to grasp more initiative in the marketing activities.

Variable cost factor refers to the magnitude of the cost change caused by an increase in the cost of production activities for some reason. The cost coefficient is based on the ratio of the previous output and consumption or the calculated value of the ratio of the output and consumption of the 
plan. Unit production cost material consumption is coefficient, it according to the production of the number of products is constantly changing and its continuous operation in the process can be constantly revised to enhance its rationality.

Penalty factor refers to the calculation of the function in the process due to not satisfy the conditions should be coupled with the coefficient. Just to punish those who does not meet the constraints of the individual, in order to solve the constrained optimization problems, the first penalty factor of penalty in constrained optimization, that is your solution must satisfy some constraints.

Parts were obtained from a supplier by a manufacturer. The total component cost of each product is $c$ from the supplier. The price is $p$ of each product sold by the manufacturer. The manufacturer faces a price-sensitive uncertain market demand. Product demand $q$ is a random variable. The product market demand is linear, and the largest market potential is $d$, which affected by product price $p$. The price sensitivity coefficient is $a$. The demand $q$ for products decreases with price-sensitive parameter $a$.

$$
\begin{aligned}
& q=d-a p \\
& \text { In Equation (1), } d, a>0 \square \frac{d}{a}>p>0
\end{aligned}
$$

In the supply chain model, price-sensitive market demand is the uniform distribution in $[q-b, q+b]$. Using a normal distribution to describe the price-sensitive uncertainty demand, one might consider which is not suitable in this context as its left tail extends into the negative demand region. The negative demand region is unrealistic. There are two commonly used remedies. One is assuming a very small coefficient of variation, and the average is a large positive number, resulting in the probability of negative demand which is very small and can be ignored. The other is the use of truncated distribution ${ }^{[9]}$. For analyzing convenience, this model uses uniformly distributed. Facing price-sensitive uncertainty demand, the probability distribution of demand expresses as $f(p / q)$. The manufacturing capability of the manufacturer is $Q$. Therefore, manufacturers expect sales can be expressed as the Equation (2).

$$
V(p, Q)=\int_{q-b}^{Q} p x f(p / q) d q+\int_{Q}^{q+b} p Q f(p / q) d q \square \square
$$

In Equation (2), the first part means market demand is less than the production volume, the second part means market demand is greater than the production volume. According to the knowledge of inventory management we can know that the demand for the product in a period of time is determined. With the change of time, the number of demand began to produce in a random changes, and in a certain time obey a distribution function, the manufacturer can through the analysis on the situation of production in the past to predict the change of market demand. Market demand is changing. Taking into account the market demand is uniform distribution in $[q-b, q+b]$. Equation (2) becomes Equation (3).

$$
\begin{aligned}
V(p, Q)= & -\frac{1}{4} \frac{p Q^{2}}{b}+\frac{1}{2} \frac{p Q(d-a p+b)}{b} \\
& -\frac{1}{4} \frac{p(d-a p-b)^{2}}{b}
\end{aligned}
$$

Manufacturer's cost $\mathrm{C}$ has two parts. One is the total cost of each product's components $c$, the other is the variable cost to produce a product, variable cost parameter, $e$. Variable costs are from increasing production costs and uncertainty caused by rising complexity of the model ${ }^{[10]}$. Manufacturer's total cost $C$ can be expressed as Equation (4).

$$
C(Q)=c Q+e Q^{2}
$$

Accurate forecast of market demand is the precondition for manufacturing enterprises to make reasonable production plan. The wrong judgment of market demand will lead to the increase of inventory costs. Customer demand is changing, such as the change of market demand, reduce the certainty of market demand. Enterprise in order to meet the needs of customers have to hoard goods for a rainy day and in this time business will use warehouse reserve a large number of products. The 
storage cost of the product is increased, the management cost of the warehouse is increased, and the manufacturing cost of the enterprise will be improved. Because of the uncertainty market demand, it appears as low demand, or unable to meet the needs. When demand is low, there will be a product backlog. The cost of each product's inventory is $s$, and the total inventory costs is $S$. When demand can't be met, the resulting shortage cost is $O$. Manufacturers cannot get the gains, resulting in potential losses, while reducing customer satisfaction, with the penalty parameter, $\lambda . \lambda$ is concerned by specific product characteristics. When the penalty parameter $\lambda$ increases, the rational choice of manufacturers is to increase inventory levels accordingly; and vice versa ${ }^{[8]}$. Inventory cost $S$ and shortage cost $O$ is as respective Equation (5) and Equation_(6).

$$
\begin{aligned}
& S(Q)=\int_{q-b}^{Q} s(Q-q) f(q / p) d q \\
& O(Q)=\int_{Q}^{q+b} \lambda(q-Q) f(q / p) d q
\end{aligned}
$$

When market demand is in the uniform distribution, Equation_(5) and Equation_(6) can be changed.

$$
\begin{aligned}
& S(Q)=\frac{1}{4} \frac{s(Q-d+a p+b)^{2}}{b} \\
& O(Q)=\frac{1}{4} \frac{\lambda(Q-d+a p-b)^{2}}{b}
\end{aligned}
$$

Therefore, the manufacturer's profit $P$ is equal to sales $V(p, Q)$ minus the total cost $C(Q)$, minus inventory cost $\mathrm{S}$ and shortage cost $O$. Manufacturer's profit can be expressed as Equation (9).

$$
P(p, Q)=V(p, Q)-C(Q)-S(Q)-O(Q)
$$

Through the analysis of the above theory and the establishment of correlation function, we know the variable relationship of profit model. We can get the profit function of uncertain conditions by compound the related function. Putting Equation (3), (4), (7) and (8) into Equation (9), Equation (10) can be gotten.

$$
\begin{aligned}
& P(p, Q)=-\frac{1}{4} \frac{p Q^{2}}{b}+\frac{1}{2} \frac{p Q(d-a p+b)}{b} \\
& -\frac{1}{4} \frac{p(d-a p-b)^{2}}{b}-c Q-e Q^{2} \\
& -\frac{1}{4} \frac{s(Q-d+a p+b)^{2}}{b} \\
& -\frac{1}{4} \frac{\lambda(Q-d+a p-b)^{2}}{b}
\end{aligned}
$$

\section{Numerical Analysis}

(1)Set the basic parameters shown in Table 1.

Table 1. values of each parameter table

\begin{tabular}{|l|l|l|l|l|l|l|l|}
\hline Parameter & $a$ & $b$ & $c$ & $d$ & $e$ & $s$ & $\lambda$ \\
\hline Value & 1 & 25 & 10 & 100 & 1 & 1 & 2 \\
\hline
\end{tabular}

(2)Putting the parameters into Equation_(10), we can obtain Equation (11).

$$
\begin{aligned}
& P(p, Q)=-\frac{1}{100} p Q^{2}+\frac{1}{50} p Q(125-p) \\
& -\frac{1}{100} p(75-p)^{2}-10 Q-Q^{2} \\
& -\frac{1}{100}(Q-75-p)^{2}-\frac{1}{100}(Q-125-p)^{2}
\end{aligned}
$$

(3)Using the Maple 11, $p$ is the $\mathrm{x}$-axis direction. $Q-p$ is the $\mathrm{y}$-axis direction. $P$ is the $\mathrm{z}$-axis direction. The ma profit curve of the manufacturer can be drawn using plot $3 d$ when demand and manufacturing costs in uncertain conditions, shown in Figure 1. The profit of the manufacturer $P$ is 
469 which can be gotten from Figure 1. Unit price of $p$ is 68. The production capacity $Q$ is 21 .

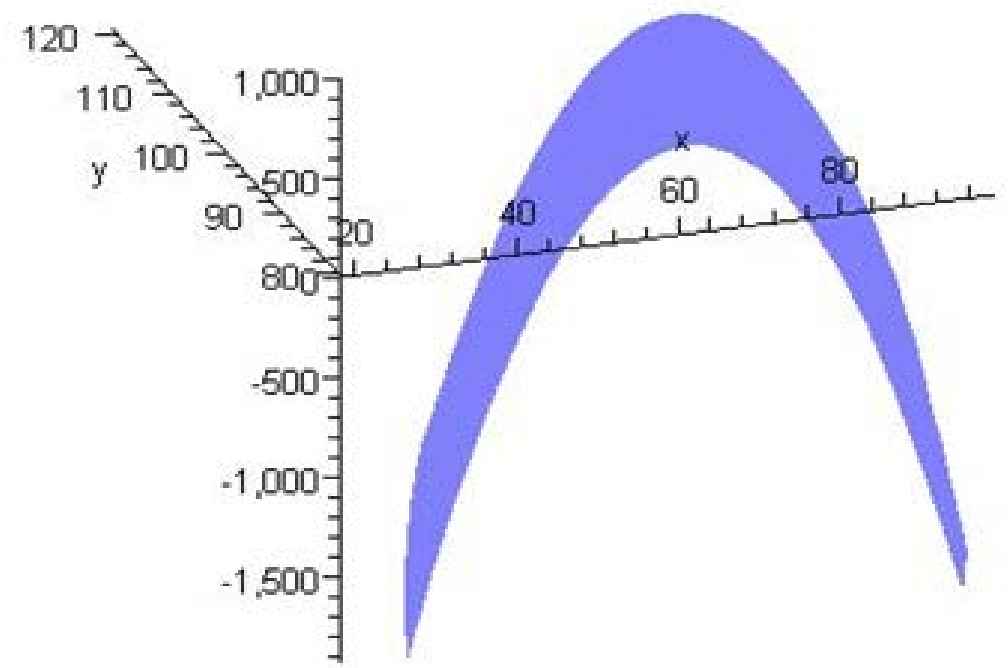

Figure 1 The profit curve of the manufacturer

According to the results of the operation can be seen manufacturer under uncertain market demand, on the basis of past sales experience in assessing the market potential value is 100, product price sensitive coefficient is 1 , the variable cost coefficient is 1 and the shortage penalty factor is 2 . The data are substituted into the formula of profit calculation can get results: in this product manufacturer is the number 21 pieces and the products for the price of 68 can obtain the biggest profit is 469 .

\section{Conclusion}

Considered a supply network consisting of a supplier and a manufacturer in this paper, profit model of the manufacturer has been established, as the market demand and manufacturing costs uncertainty, analyzing the characteristics of that supply and demand matched badly the manufacturer facing. The model assumes that price-sensitive products in the uncertain market demand, the demand is uniformly distributed within a certain range, the cost of production with the production different changes, taking account of poor sales due to inventory costs and supply shortages caused by lack of cost. By numerical simulation, profit curve of the manufacturer and maximum profits was attained. The feasibility of the model was proved. This model provides a reference to the manufacturer in the supply network under the price and quantity of products uncertainty. In the complex supply chain network, customer demand, resource supply, production organization, logistics and sales, there are uncertainties. Leading enterprises in order to improve business operation income should reduce the logistics operating costs, improve transport efficiency, needs to adapt to the changing times and the technological development and progress. It is useful to improve warehousing and logistics equipment and technology level. Enterprises need to accurately grasp the market demand, timely adjustment of production planning.

Through the research on the profit model of the supply chain leading enterprises under the uncertain conditions is significant to the future development of the enterprise. The enterprise can make forecast to the market demand through the analysis of the external environment and make the reasonable production plan. Manufacturers can predict the production of the enterprise and make the estimation of the cost in advance, optimize the inventory management and reduce inventory costs.

\section{Acknowledgement}

This paper was supported by the science and technology innovation fund of Henan Agricultural University, China (Grant No. KJCX2016A04), Henan province science and technology research project, China (Grant No. 16210211012). The first author is the corresponding author. 


\section{References}

[1] Ellarm, L.M., Cooper, M.C. "Supply chain management, partnerships and the shipper-third party relationship”. The international Journal of Logistics management, 1990,(1), pp.1-10

[2] Rockhold, S., Lee, H., Hall, R. "Strategic alignment of a global supply chain for business success”. Global supply chain and Technology Management, FL, pp.16-29, (1998).

[3] Beamon B M. "Measuring Supply China Performance”. International Journal of Operations of Production Management, 1999,19(3), pp. 275-292.

[4] Wang Guang-yu, Ding Hua-ming. “Activity based costing management”. [J]. Beijing Tsinghua University press,2009, pp.103-106

[5] Chung-Chi Hsieh, Cheng-Han Wu. "Capacity allocation, ordering, and pricing decisions in a supply chain with demand and supply uncertainties”.[J]. European Journal of Operational Research, 2008,(184), pp. 667-684.

[6] Hu Jia. "Profit model analysis and coordination strategy of enterprise supply chain under market economy”.[J]. Logistics engineering and management,2013,35 (9),pp.121-123.

[7] Li Gui-chun. "Study on the coordination mechanism of distributed service supply chain system”.[J]. Logistics technology,2016, (3),pp.139-142.

[8] Ann Zhong-hua. “Commodity sales profit model based on Markov chain”. [J]. Contemporary economy,2014, (15),pp.126-127

[9] Haluk Demirkan, Hsing Kenneth Cheng. "The risk and information sharing of application services supply chain”. European Journal of Operational Research,2008, (187), pp. 765-784

[10]Cotton, I.W. "Microeconomics and the market for computer services”. Computing Surveys, 1975,7(2), pp. 95-111.

[11]Zhou Xiao-zhuang, Zhao Yu-hua. “Study on the Penalty Mechanism of JIT Supply Chain”. East China Economic Management,2006, 20(2), pp. 97-99.

[12]Cui Jia. “An analysis of uncertainty management in supply chain”. [J]. Internet of things technology, 2016,(5),pp.106-108.

[13]Gao Xi-hua. “The supply chain profit maximization”. [J]. Financial economy under uncertain circumstances,2016,(10),pp.130-132.

[14]Dong Peng. "Research on the production planning and control based on the supply chain management plan”. [J]. Paper information, 2015,(12),pp.10-14.

[15]Wang Lan. "Study on the relationship between supply chain uncertainty, organizational learning and supply chain performance”.[J]. Logistics technology, 2016,(4),pp.129-133+138.

[16]Zhao Ming, Zhang Yan. "Profit sharing model of supply chain under the participation of transport companies". [J]. Journal of Foshan University (NATURAL SCIENCE EDITION),2016,34 (1),pp.30-34. 